\title{
LA EJECUCIÓN FORZOSA DE LAS RESOLUCIONES JUDICIALES EN EL MARCO DE LOS REGLAMENTOS EUROPEOS*
}

\author{
Pilar JiMÉNEZ BLANCO **
}

SUMARIO: 1. EL CONTEXTO DE LA EJECUCIÓN FORZOSA.-2. EL PRESUPUESTO DE LA FUERZA EJECUTIVA EN ORIGEN.-2.1. Extensión de los efectos y fuerza ejecutiva en origen.-2.2. La caducidad de la acción ejecutiva.-3. COMPETENCIA E INICIO DE LA EJECUCIÓN.-3.1. Juez competente para la ejecución.-3.2. Requisitos documentales.-3.2.1. Función de los certificados.-3.2.2. Requisitos de traducción.-3.2.3. Notificaciones y despacho de ejecución.-3.3. Régimen de las medidas cautelares.-3.3.1. Medidas cautelares dictadas por el tribunal de origen.-3.3.2. Medidas cautelares dictadas por el tribunal de ejecución.-4. OPOSICIÓN Y SUSPENSIÓN DE LA EJECUCIÓN.-4.1. Impugnación del título en el Estado de origen e incidencia en la ejecución.-4.2. Impugnación del título en el Estado de la ejecución.-4.3. La oposición a la ejecución.-5. CONCLUSIONES.

\section{EL CONTEXTO DE LA EJECUCIÓN FORZOSA}

1. La ejecución forzosa de las resoluciones judiciales está vinculada al principio de territorialidad que impide, por razones de soberanía, que un Estado pueda realizar actos de coerción dentro de otro Estado, criterio reforzado por la competencia exclusiva existente en esta materia ${ }^{1}$. Así, la adopción de actos ejecutivos concretos en otro Estado requiere su reconocimiento y ejecución en el mismo, eligiendo el demandante acreedor el locis executionis ${ }^{2}$

\footnotetext{
* Este trabajo se adscribe al Proyecto de Investigación I+D+I del MINECO Ref. DER2017-86107-R, del que son Investigadores Principales EsPiniella MEnÉndez, A. y Jiménez Blanco, P., de la Universidad de Oviedo.

** Profesora Titular de Derecho internacional privado en la Universidad de Oviedo (pilarj@ uniovi.es).

1 Véase el art. 22.e) de la Ley Orgánica del Poder Judicial (BOE núm. 157, de 2 de julio de 1985, en adelante, LOPJ) y el art. 24.5 del Reglamento (UE), núm. 1215/2012, del Parlamento Europeo y del Consejo, de 12 de diciembre, relativo a la competencia judicial, el reconocimiento y la ejecución de resoluciones judiciales en materia civil y mercantil (DO L núm. 351, de 20 de diciembre de 2012) (a partir de aquí, Bruselas I bis).

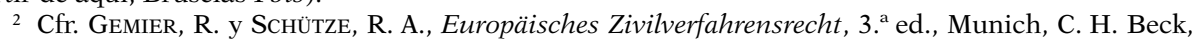
2010, p. 432.
} 
en función de la localización de los bienes o de la actividad sobre la que recae la condena ${ }^{3}$.

En el marco del Derecho europeo vigente, el procedimiento de ejecución forzosa sigue siendo esencialmente nacional ${ }^{4}$ y se mueve entre dos principios: la extensión de los efectos de la decisión de origen al Estado de la ejecución ${ }^{5}$ y la asimilación a las decisiones nacionales en cuanto al procedimiento y las condiciones de la ejecución ${ }^{6}$.

2. Los instrumentos europeos parten de dos grandes modelos para establecer cuándo existe un título ejecutivo en el Estado de la ejecución: el de la declaración de fuerza ejecutiva o exequátur ${ }^{7} \mathrm{o}$ el de la fuerza ejecutiva directa de la resolución sin ese procedimiento intermedio. Dentro de este último, son identificables, a su vez, tres submodelos de fuerza ejecutiva inmediata: la basada en un certificado europeo que difiere de la resolución de origen, sin posibilidad de impugnación del título en el Estado requerido (modelo del título ejecutivo europeo $)^{8}$; la basada en la resolución nacional de origen, pero con posibilidad de impugnación del título en el Estado de la ejecución (modelo de Bruselas I bis $)^{9}$; y la basada en la resolución nacional de origen sin posibilidad de impugnación del título en el Estado de la ejecución (modelo del Reglamento de alimentos para resoluciones dictadas por Estados vinculados por el Protocolo de La Haya de 2007) ${ }^{10}$.

\footnotetext{
3 Cfr. Remien, O., Rechtsverwirklichung durch Zwangsgeld, Tübingen, J. C. B. Mohr (Paul Siebeck), 1992, pp. 301-302; STADLER, A., «Inländisches Zwangsgeld bei grenzüberschreitender Handlungsvollstreckung», IPRax, 2003, pp. 430 y ss., esp. p. 432. La ejecución directa debe distinguirse de la indirecta, es decir, cuando ante el incumplimiento de una resolución, el órgano que la dictó adopta determinadas medidas para intentar asegurar y compeler a ese cumplimiento sin que esas medidas supongan, de manera inmediata, la realización de actos ejecutivos (por ejemplo, de multas coercitivas).

4 Véase en esta clave el art. 41 de Bruselas I bis en relación con la regla 3. a del apartado 2 de la disposición final (DF) 25 LEC; el art. 47 del Reglamento (CE) núm. 2201/2003, del Consejo, de 27 de noviembre, relativo a la competencia judicial, el reconocimiento y la ejecución de resoluciones judiciales en materia matrimonial y de responsabilidad parental ( $D O$ L núm. 338, de 23 de diciembre de 2003) (a partir de aquí, Bruselas II bis); el art. 20 del Reglamento (CE) núm. 805/2004, del Parlamento Europeo y del Consejo, de 21 de abril, por el que se establece un título ejecutivo europeo para créditos no impugnados (ibid. L núm. 143, de 30 de abril de 2004); el art. 41 del Reglamento (CE) núm. 4/2009, del Consejo, de 18 de diciembre de 2008, relativo a la competencia judicial, el reconocimiento y la ejecución de resoluciones judiciales y la cooperación en materia de obligaciones de alimentos (ibid. L núm. 7, de 10 de enero de 2009).

5 Cfr. STJCE en el asunto C267/97 (Coursier, ECLI:EU:C:1999:213, apdo. 23); y STJUE en el asunto C-139/10 (Prism Investments, ECLI:EU:C:2011:653, apdo. 38).

6 Véase el considerando 26 de Bruselas I bis; NuYTs, A., "La refonte du règlement Bruxelles I», Rev. crit. dr. int. pr., 2013, pp. 21 y ss., esp. p. 102, apartado 15.

7 Modelo presente en el art. 26 del Reglamento núm. 4/2009, art. 43 del Reglamento (UE) núm. 650/2012, del Parlamento Europeo y del Consejo, de 4 de julio, relativo a la competencia, la ley aplicable, el reconocimiento y la ejecución de las resoluciones, a la aceptación y a la ejecución de los documentos públicos en materia de sucesiones mortis causa y a la creación de un certificado sucesorio europeo (DO L núm. 201, de 27 de junio de 2012) y art. 28 del Reglamento Bruselas II bis. No obstante, debe tenerse en cuenta la Propuesta de revisión de este último, que elimina también el exequátur para las decisiones sobre responsabilidad parental, véase Documento $\operatorname{COM(2016)} 411$ final.

8 Reglamento (CE) núm. 805/2004 y arts. 41 y 42 de Bruselas II bis.

9 Este es también el modelo que pretende introducirse en la reforma de Bruselas II bis; véase el Documento COM (2016) 411 final. 
En este contexto, los Reglamentos europeos, además de compartir conceptos y ciertos presupuestos comunes ${ }^{11}$, introducen una armonización mínima en materia de ejecución forzosa que debe ser respetada, sin que quepa la aplicación de los Derechos nacionales en términos de norma más favorable o favor executionis ${ }^{12}$. No obstante, ese «cuerpo común» de la ejecución transfronteriza presenta en ocasiones diferencias poco compatibles con el establecimiento de unos estándares europeos mínimos. Siendo cierto que el deudor ejecutado no debería verse beneficiado del mismo grado de tutela que el demandado en el proceso declarativo ${ }^{13}$, ello no justifica ciertas diferencias en el régimen de protección de sus derechos de defensa. A identificar las pautas comunes entre los instrumentos europeos y las diferencias no justificadas se dedicarán las líneas que siguen.

\section{EL PRESUPUESTO DE LA FUERZA EJECUTIVA EN ORIGEN}

\subsection{Extensión de los efectos y fuerza ejecutiva en origen}

3. La aplicación práctica más importante de la extensión de los efectos se constata en la fuerza ejecutiva de la resolución en origen como presupuesto para su ejecución. La fuerza ejecutiva en origen debe ser un requisito controlable de oficio por parte del juez encargado de la ejecución y, en su caso, la falta de fuerza ejecutiva también podrá hacerse valer por el deudor ejecutado, al amparo del art. 559.1.3 de la Ley de Enjuiciamiento Civil ${ }^{14}$ (en adelante, LEC) ${ }^{15}$. La fuerza ejecutiva se ha interpretado, en el contexto del Reglamento Bruselas I, «en términos formales», de modo que no abarca los supuestos que pueden impedir, a posteriori, la ejecución de una sentencia (como, por ejemplo, el pago) ${ }^{16}$. Esta interpretación del TJUE deberá extenderse al resto de los Reglamentos europeos. Desde la perspectiva procedimental, ello supone que la oposición a la ejecución en el caso concreto no puede hacerse valer en la fase de exequátur (de existir esta) sino en la fase de ejecución forzosa ${ }^{17}$.

10 Art. 17 del Reglamento núm. 4/2009. También es el modelo seguido en los procedimientos europeos recogidos en el Reglamento (CE) núm. 1896/2006, del Parlamento Europeo y del Consejo, de 12 de diciembre, por el que se establece un proceso monitorio europeo ( $D O$ núm. L 399, de 30 de diciembre de 2006) y en el Reglamento (CE) núm. 861/2007, del Parlamento Europeo y del Consejo, de 11 de julio, por el que se establece un proceso europeo de escasa cuantía (ibid. L núm. 199, de 31 de julio de 2007).

11 Véase la idea de transponer interpretaciones en REQUEJO IsIDRO, M., "La ejecución sin exequátur. Reflexiones sobre el Reglamento Bruselas I bis, Capítulo III», REDI, vol. 67, 2015-2, pp. 49 y ss., esp. pp. 69-71.

12 Ello puede matizarse en algún punto. Se ha defendido, por ejemplo, la posible aplicación de los Derechos nacionales como más favorables si permiten la ejecución de medidas provisionales dictadas inaudita parte, véase NuYTs, A., op. cit., nota 6, pp. 43-44.

13 Véase ReQueJo Isidro, M., op. cit., nota 11, p. 66, nota 64.

14 BOE núm. 7, de 8 de enero de 2000.

15 Véase párr. 29.

16 Véase la STJCE en el asunto C-267/97 (Coursier), en relación con la invocación de una inmunidad del deudor en el Estado de origen derivada de una declaración de quiebra.

17 Véase la STJCE en el asunto C-139/10 (Prism Investments). 
Desde la perspectiva de la ley aplicable, significa que las causas que pueden impedir la ejecución en el caso concreto dependen de la ley del Estado requerido, sin que puedan acumularse los motivos de la ley de origen ${ }^{18}$.

Todos los instrumentos europeos desactivan el art. 525 LEC para la ejecución transfronteriza, posibilitando la ejecución provisional de resoluciones no firmes: en unos casos, si así lo permite la ley del Estado de origen de la resolución; en otros casos, como una imposición directa de la propia normativa europea, al margen del Derecho nacional de origen ${ }^{19}$.

4. El presupuesto de la fuerza ejecutiva puede verse comprometido si, una vez iniciado el procedimiento de ejecución en el Estado requerido (o el exequátur, si este resulta exigible) se suspendiera o limitara dicha fuerza ejecutiva en el Estado de origen ${ }^{20}$. En coherencia, una suspensión de la fuerza ejecutiva en origen debería determinar, de manera preceptiva, una suspensión de la ejecución en el Estado requerido ${ }^{21}$. En este contexto, el principio de la extensión de los efectos es una pauta hermenéutica útil para derivar esta suspensión de la fuerza ejecutiva aunque algún instrumento, como ocurre de Bruselas II bis, no lo establezca expresamente ${ }^{22}$ y así se recoge en su Propuesta de reforma ${ }^{23}$. En todo caso, la construcción de la

18 Mankowski, P., «Art. 44 Brüssel Ia-VO», en Rauscher, Th. (coord.), Europäisches Zivilprozessrecht- und Kollisionsrecht (EuZPR/EuIPR) Kommentar, vol. I, 4. ${ }^{\text {a }}$ ed., Colonia, Dr. Otto Schmidt, 2016, pp. 1063 y ss., esp. p. 1073.

19 Véanse el considerando 22 y el art. 39 del Reglamento núm. 4/2009; art. 41.1 de Bruselas II bis; art. 18 del Reglamento núm. 1896/2006 y art. 15 del Reglamento núm. 861/2007.

${ }^{20}$ No todo recurso en el Estado de origen equivale a una suspensión de la fuerza ejecutiva. Esta podría producirse, por ejemplo, por la pendencia de un recurso de rescisión de una sentencia en rebeldía (véanse, para el Derecho español, los arts. 505 y 566 LEC).

21 Esta es la solución expresamente prevista en el Reglamento Bruselas I bis (art. 44.2 en relación con la DF 25 LEC, apdo. 4, regla 3. ${ }^{\text {) }}$. Véase Cuniberti, G. y RuEdA, I., "Article 44», en Magnus, U. y Mankowski, P., European Commentaries on Private International Law (ECPIL), Brussels I bis Regulation, vol. I, Colonia, Dr. Otto Schmidt, 2016, pp. 859 y ss., esp. pp. 862-863, que lo ven como un verdadero derecho del deudor [véase también Franzina, P., Kramer, X. y Fitchen, J., «The Recognition and Enforcement of Member State Judgments», en Dickinson, A. y LeIN, E. (eds.), The Brussels I Regulation Recast, Oxford, OUP, 2015, pp. 373 y ss., esp. p. 431; y MANKOWSKI, P., op. cit., nota 18, pp. 1072-1073]. En el mismo sentido, los arts. 21.2 y 35 del Reglamento de alimentos [ANDRAE, M. y SCHIMRICK, M., "Art. 21 EG-UntVO», en RAUScher, Th. (coord.), Europäisches Zivilprozessrecht- und Kollisionsrecht (EuZPR/EuIPR) Kommentar, vol. IV, 4. a ed., Colonia, Dr. Otto Schmidt, 2015, pp. 647 y ss., esp. p. 655]; también el art. 53 del Reglamento núm. 650/2012; el art. 52 del Reglamento (UE) núm. 2016/1103, del Consejo, de 24 de junio, por el que se establece una cooperación reforzada en el ámbito de la competencia, la ley aplicable, el reconocimiento y la ejecución de resoluciones en materia de regímenes económicos matrimoniales (ibid. L núm. 183, de 8 de julio de 2016); y art. 52 del Reglamento (UE) núm. 2016/1104, del Consejo, de 24 de junio, por el que se establece una cooperación reforzada en el ámbito de la competencia, la ley aplicable, el reconocimiento y la ejecución de resoluciones en materia de efectos patrimoniales de las uniones registradas (ibid.).

22 En relación con el art. 28 del Reglamento Bruselas II bis, véase McLEAN, D., "Article 28», en Magnus, U. y Mankowski, P., European Commentaries on Private International Law, Brussels II bis Regulation, Munich, Sellier, 2012, pp. 293 y ss., esp. p. 294. El art. 35 de Bruselas II bis solo prevé una suspensión potestativa para los casos de recurso (o posibilidad de recurso) de la decisión en el Estado de origen, lo que no equivale necesariamente a una suspensión de la fuerza ejecutiva en origen si el recurso no produjera tal efecto en aquel Estado.

${ }^{23} \mathrm{El}$ art. 36 de la Propuesta de reforma de este Reglamento [Documento $\operatorname{COM}(2016) 411$ final] ya incorpora esta suspensión de manera imperativa. 
extensión de los efectos se encuentra limitada en la práctica, dada la imposibilidad de que el juez encargado de la ejecución pueda conocer las vicisitudes de la resolución en origen, debiendo ser siempre invocada por el deudor ejecutado ${ }^{24}$.

\subsection{La caducidad de la acción ejecutiva}

5. Problemas diferentes plantea la caducidad de la acción ejecutiva. Los Reglamentos europeos, salvo el de alimentos, no se pronuncian expresamente al respecto ${ }^{25}$. La determinación de la ley aplicable a la caducidad de la acción ejecutiva no es una cuestión pacífica, existiendo argumentos tanto a favor de la aplicación de la ley del Estado de origen como de la ley del Estado de la ejecución, pudiendo además plantearse la cuestión de si el plazo es de prescripción o de caducidad ${ }^{26}$.

Una solución basada en la aplicación indiscriminada del art. 518 LEC, como ley del Estado de la ejecución, a la caducidad de la acción ejecutiva de una resolución extranjera resulta criticable. Por una parte, es una solución poco acorde con la dilación de las ejecuciones transfronterizas, que generalmente serán subsidiarias respecto de la ejecución nacional y tendrán más vicisitudes procesales si requieren exequátur previo. Además, la determinación del locus executionis por parte del acreedor introduciría un elemento de inseguridad para el deudor sobre la vigencia de su obligación. Por otra parte, deben considerarse los desajustes que podrían producirse si el plazo establecido en la ley española difiere del de la ley del Estado de origen, que abocaría a soluciones no conformes con la extensión de los efectos de la resolución extranjera: si el plazo del Derecho español es más largo, se dotaría de eficacia ejecutiva a una decisión extranjera que ya no la tiene; si el plazo del Derecho español es más corto, se privaría de eficacia a una resolución plenamente ejecutiva en el Estado de origen. Tampoco el establecimiento de un plazo de caducidad específico, aplicado a resoluciones extranjeras, sería una buena solución, en la medida en que podrían seguir existiendo desajustes con la ley de origen.

En consecuencia, la única solución coherente con la extensión de los efectos de la resolución extranjera sería la aplicación de la ley del Estado de origen para determinar el plazo de caducidad (o de prescripción) de la misma. Sería irrelevante si la resolución de origen requiere exequátur o es ejecutiva directamente, dado que el presupuesto de la fuerza ejecutiva es el mismo y, en

24 ANDRAE, M. y SchimricK, M., op. cit., nota 21, p. 654.

25 La aplicación de la ley del Estado de origen es la solución también defendida para el título ejecutivo europeo; véase Garcimartín Alférez, F. J., El título ejecutivo europeo, Navarra, Thomson/Civitas, 2006, pp. 119-120; y Gascón Inchausti, F., El título Ejecutivo Europeo para Créditos No Impugnados, Navarra, Thomson/Aranzadi, 2005, p. 109.

${ }^{26}$ A favor de la ley del origen, estaría entender que se trata de una cuestión vinculada al carácter ejecutable del título; a favor de la lex fori, considerar que solo el exequátur dota de fuerza ejecutiva a la resolución en el foro (REQUEJo IsIDRO, M., op. cit., nota 11, p. 67). 
todos los casos, el dies a quo para el cómputo del plazo será el de la firmeza de la decisión ${ }^{27}$.

6. La regla general de la aplicación de la ley de origen requiere una matización para las resoluciones de alimentos que tienen fuerza ejecutiva directa, para las que el art. 21.2 del Reglamento de alimentos prevé la aplicación de la ley del Estado de ejecución si establece un plazo más largo de prescripción (sic), lo que, en clave favor creditoris, permitiría ejecutar una decisión que ya no tiene carácter ejecutivo en origen. Es significativo que esa finalidad tuitiva del acreedor solo se manifieste respecto de resoluciones procedentes de Estados parte del Protocolo de La Haya de 2007, permaneciendo la regla general sobre fuerza ejecutiva en el resto de los casos en los que dicha orientación material no está presente.

\section{COMPETENCIA E INICIO DE LA EJECUCIÓN}

\subsection{Juez competente para la ejecución}

7. Los Reglamentos europeos ni establecen ni prejuzgan las reglas de competencia nacionales sobre el procedimiento de ejecución forzosa, ni siquiera que dicha competencia, con carácter general, tenga que estar atribuida a un órgano jurisdiccional ${ }^{28}$; solo se han fijado reglas de competencia territorial para el exequátur ${ }^{29}$.

Para las resoluciones que requieran exequátur, la competencia para ejecutar debería entenderse atribuida al mismo Juzgado competente para decidir sobre el exequátur. Si ambas pretensiones se presentan conjuntamente, conforme al art. 545 LEC, el mismo tribunal competente para el exequátur lo será también para iniciar el procedimiento de ejecución forzosa ${ }^{30}$. A la

27 STS (Sala de lo Civil, Sección 1. a), de 16 de octubre de 2014 (RJ 2014/5813). En otros sistemas, es la fecha del exequátur el dies a quo, véase en REQueJo IsIDRo, M., op. cit., nota 11, p. 67.

${ }_{28}$ Existe, en este punto, una libertad de autoorganización de los Estados [MANKowsKI, P., «Art. 41 Brüssel Ia-VO», en RAUSCHER, Th. (coord.), Europäisches Zivilprozessrecht- und Kollisionsrecht (EuZPR/

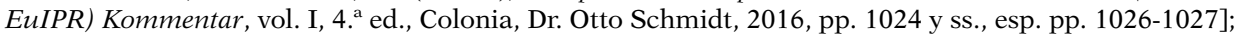
véase una perspectiva de Derecho comparado sobre ejecución en HESs, B., «Study No. JAI/A3/2002/02 on making more efficient the enforcement of judicial decisions within the European Union: Transparency of Assets, Attachment of Bank Accounts, Provisional Enforcement and Protective measures», 2004, http://ec.europa.eu/civiljustice/publications/docs/enforcement_judicial_decisions_180204_en.pdf. Cuestión distinta es que se reserven a los órganos jurisdiccionales la decisión sobre determinados extremos: por ejemplo, la denegación de la ejecución en el art. 47 de Bruselas I bis.

${ }_{29}$ El domicilio de la parte contra la que se solicita ejecución o el lugar de ejecución estaban en el art. 39.2 del Reglamento Bruselas I [Reglamento (CE) núm. 44/2001] y son los vigentes en el art. 27.2 del Reglamento núm. 4/2009, art. 45 del Reglamento núm. 650/2012, art. 44.2 del Reglamento núm. 2016/1003 y art. 44.2 del Reglamento núm. 2016/1104. Por su parte, el art. 29.2 de Bruselas II bis parte de la subsidiariedad entre estos dos criterios, de modo que el lugar de ejecución solo opera si la persona frente a la que se solicita la ejecución, o los menores, no tienen su residencia habitual en el Estado de la ejecución.

${ }^{30}$ Cfr. Gascón Inchausti, F., «Reconocimiento y ejecución de resoluciones judiciales extranjeras en la Ley de cooperación jurídica internacional», Cuadernos de Derecho Transnacional (CDT), vol. 7, 2015, núm. 2, pp. 158 y ss., esp. p. 172. 
misma solución cabe llegar aunque la demanda de ejecución no se haya acumulado a la solicitud de exequátur ${ }^{31}$, descartando la aplicación en este caso del art. 545.3 LEC $^{32}$. Además, esta competencia por conexidad del juez que conoció del exequátur permite una mejor adaptación a la ejecución, considerando que pueden ser procesos paralelos (cuando el exequátur no sea aún firme) y que puede ser conveniente que sea el mismo juez el que valore las causas de denegación del exequátur y de oposición a la ejecución.

Respecto a la competencia objetiva, los mismos argumentos antes expuestos para la competencia territorial servirían para defender la competencia por conexidad para la ejecución a los Juzgados de Primera Instancia o los Juzgados de lo Mercantil que hubieran conocido del exequátur, conforme al art. 86.ter LOPJ. Evitando, entre otras cuestiones la distorsión de mantener la declaración de fuerza ejecutiva en los Juzgados de Primera Instancia y la ejecución propiamente dicha en los Juzgados de lo Mercantil ${ }^{33}$.

8. En el caso de las resoluciones judiciales de ejecución directa, la inexistencia de "contacto" previo con algún órgano jurisdiccional español excluye la aplicación del art. 545.1 LEC respecto a la competencia territorial. En estos casos, las resoluciones ejecutivas dictadas por tribunales de otros Estados UE podrían encajar en la ejecución de «títulos distintos de los expresados en los apartados anteriores» del art. 545.3 LEC y será competente el Juzgado de Primera Instancia del lugar determinado por los arts. 50 y 51 de la LEC o, a elección del ejecutante, del lugar de cumplimiento de la obligación o de situación de los bienes. No obstante, la aplicación de este art. 545.3 LEC plantea dos tipos de problemas. El primero, es que este precepto abre la opción a la ejecución en el domicilio del actor, si el demandado no está ni ha estado domiciliado ni ha residido en España, criterio cuestionable y sin precedentes en el ámbito de la ejecución de los litigios transfronterizos ${ }^{34}$. El segundo, es un problema de falta de homogeneidad entre este art. 545.3 LEC con las reglas de competencia territorial especiales dictadas en las disposiciones finales de la LEC para la ejecución del título ejecutivo europeo para créditos no impugnados (que parten de la alternatividad del domicilio del demandado o del lugar de ejecución) ${ }^{35}$ y con las dictadas para el monitorio europeo y de un proceso europeo de escasa cuantía (que parten exclusivamente del criterio del domicilio del demandado, sin mencionar el lugar de ejecución) ${ }^{36}$. Resultan injustificadas estas diferencias, por lo que tales criterios no deberían entenderse excluyentes del art. 545.3 LEC.

31 En esta clave, Virgós Soriano, M. y Garcimartín Alférez, F. J., Derecho Procesal Civil Internacio-

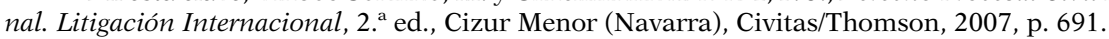

${ }^{32}$ Defienden la aplicación del art. 545.3 LEC, GASCón INCHAUSTI, F., op. cit., nota 30, pp. 172-173; REQUEJo IsIDRo, M., op. cit., nota 11, p. 74, nota 98

33 Véase Jiménez Blanco, P., «Ejecución de sentencia extranjera. Comentario a la Sent. Aud. Prov. de Cádiz (Sección 7. ${ }^{\text {) }}$ ) de 12 de julio de 2007», REDI, vol. LX, 2008, núm. 1, pp. 236 y ss.

34 En todo caso, también hay que considerar que la exorbitancia de la competencia no ha de medirse de la misma manera en el proceso declarativo que en la fase de ejecución forzosa.

${ }_{35}$ Cfr. la DF 21, apartado 5 LEC.

36 Cfr. las DDFF 23 y 24 LEC. 
Respecto a la competencia objetiva, las disposiciones finales de la LEC mantienen también, sorprendentemente, soluciones diversas: para el monitorio europeo se establece la competencia «exclusiva y excluyente» de los Juzgados de Primera Instancia (fase declarativa) que luego se extiende a la ejecución; para la escasa cuantía se establece la competencia del Juzgado de Primera Instancia o de lo mercantil (fase declarativa), en función del objeto de la reclamación, pero para la ejecución solo se refiere a Juzgado de Primera Instancia ${ }^{37}$. Por su parte, para Bruselas I bis, la DF 25 LEC atribuye la competencia, para la denegación de la ejecución, al mismo juzgado que estuviera conociendo de la ejecución (sin predeterminar la competencia objetiva); sin embargo, el órgano que se ha comunicado en el marco del art. 75 de Bruselas I bis para denegar la ejecución es el «Juzgado de Primera Instancia», lo que parece excluir una eventual competencia de los Juzgados de lo mercantil ${ }^{38}$. La coherencia interna del sistema (sin inconvenientes en contra) obligaría a entender aplicables los mismos criterios para la competencia declarativa y la ejecutiva y sin discriminación entre títulos nacionales y títulos extranjeros ${ }^{39}$.

\subsection{Requisitos documentales}

\subsubsection{Función de los certificados}

9. La documentación que debe acompañar la demanda ejecutiva es la resolución judicial de origen y el certificado previsto en los diferentes Reglamentos, que, no obstante, tienen características y alcance diverso.

10. En los modelos de exequátur, en el ámbito de familia y sucesiones, el certificado tiene un carácter meramente probatorio, siendo un documento subsanable por otros medios de prueba y carente de verdadero valor vinculante, en cuanto a su contenido, para los órganos del Estado de la ejecución ${ }^{40}$. Salvo prueba en contra, dicho documento permite acreditar la fuerza ejecutiva de la resolución en origen y la notificación en los procesos en rebeldía.

11. En todos los modelos de fuerza ejecutiva directa, el certificado es preceptivo e insustituible, sin que en ningún caso pueda apelarse al Derecho nacional en clave de favor executionis para flexibilizar tal exigencia ${ }^{41}$.

\footnotetext{
37 Véanse DDFF 23, apartados 1 y 13, y 24, apartados 1 y 7 LEC.

38 https://e-justice.europa.eu/content_brussels_i_regulation_recast-350-es-es.do?member=1 (consultada el 30 de octubre de 2017).

39 Lo mismo se ha defendido para el ámbito concursal, EsPInIELla MEnÉndez, A., «La ¿inocente? Actualización del Reglamento (CE) núm. 1346/2000, sobre procedimientos de insolvencia», REDI, vol. LVII, 2005, núm. 1, pp. 529 y ss., esp. p. 532.

40 Es el modelo de Bruselas II bis (arts. 37 y 39), del Reglamento núm. 650/2012 (arts. 46 y 47), de las resoluciones de alimentos que requieren exequátur (art. 29 del Reglamento núm. 4/2009); y de los Reglamentos núms. 2016/1103 y 2016/1104 (arts. 45.3 y 46).

${ }^{41}$ Es decir, no cabría en estos casos invocar la mayor flexibilidad probatoria permitida por el art. 54.4.c) de la Ley 29/2015, de Cooperación Jurídica Internacional en Materia Civil (BOE núm. 182, de 31 de julio de 2015).
} 
No obstante, también aquí cabe identificar diferentes características. El certificado asume un carácter claramente constitutivo para el título jurídico europeo, que se expide después de haber superado el control de condiciones en el Estado de origen, y que difiere del título o resolución nacional, siendo precisamente ese certificado el que «europeiza» la decisión y la dota de la fuerza ejecutiva necesaria para desplegar la eficacia en el Estado requerido ${ }^{42}$. Entran aquí el título ejecutivo europeo para créditos no impugnados y los relativos a derecho de visita y restitución de menores de Bruselas II bis. Estos certificados tienen un valor vinculante pleno para las autoridades del Estado requerido, pudiendo ser solo atacados ante las autoridades del Estado de origen por las vías previstas ad hoc en el Estado de origen ${ }^{43}$.

En Bruselas I bis y en las resoluciones de alimentos con fuerza ejecutiva directa, el certificado es preceptivo pero no constitutivo, dado que el título sigue siendo exclusivamente la resolución de origen ${ }^{44}$. Su función es habilitante para la ejecución, pero meramente probatoria en cuanto a su contenido, careciendo de fuerza vinculante. Ese mismo carácter no vinculante, afirmado en Trade Agency (asunto C-619/10) respecto de Bruselas I ${ }^{45}$, puede ser trasvasado a Bruselas I bis. Así, la información sobre la notificación del proceso de origen, contenida en el certificado de Bruselas I bis, puede desvirtuarse por el deudor en la fase de ejecución. La ausencia de carácter vinculante en Bruselas I bis hace irrelevante e innecesaria la impugnación por inexactitud de dicho certificado en el Estado de origen. Lo mismo sucede en relación con el certificado de las resoluciones de alimentos: el deudor puede demostrar la inexactidud de su contenido y, en caso de discrepancia del certificado con la resolución de base, esta será la que deba prevalecer ${ }^{46}$.

42 El certificado del título ejecutivo europeo es el «salvaconducto» que permite la libre circulación de la resolución judicial certificada (GARCIMARTín ALFÉREZ, F. J., op. cit., p. 170). La resolución que se reconoce es el «título europeo» (EsPinIElla MEnÉndez, A., «La “europeización” de decisiones de Derecho privado", REDI, vol. LX, 2008-1, pp. 39 y ss.).

43 Véase el art. 10 del Reglamento núm. 805/2004 y el art. 43 de Bruselas II bis, véase MAgNus, U., «Article 43», en Magnus, U. y MankowsKi, P., Brussels II Bis..., op. cit., p. 370.

${ }^{44}$ Franzina, P., Kramer, X. y Fitchen, J., loc. cit., pp. 501-502, destaca este carácter obligatorio; en el mismo sentido, ReQueJo IsIDro, M., op. cit., nota 11, p. 56, y PoHL, M., «Die Neufassung der EuGVVO - im Spannungsfelds zwischen Vertrauen und Kontrolle», IPRAx, 2013, pp. 109 y ss., esp. p. 113, llegándose a referir a él como un verdadero «pasaporte judicial» [MANKOwsKI, P., «Art. 42 Brüssel IaVO», en RAuscher, Th. (coord.), Europäisches Zivilprozessrecht- und Kollisionsrecht (EuZPR/EuIPR) Kommentar, vol. I, 4. ${ }^{\text {a }}$ ed., Colonia, Dr. Otto Schmidt, 2016, pp. 1036 y ss., esp. p. 1040]. En el mismo grupo cabe incluir a las resoluciones dictadas en el ámbito de los procesos monitorios europeos y de escasa cuantía.

45 En relación con el antecedente en el Reglamento Bruselas I, véase GEIMER, R. y SchÜTZE, R. A., op. cit., p. 825. Véase la STJUE en el asunto 619/10: Trade Agency y el comentario de JimÉnEz BLANCO, P., "¿Vulnera el orden público una resolución judicial no motivada dictada en rebeldía del demandado?», La Ley: Unión Europea, 2013, núm. 1, pp. 39-48.

${ }^{6}$ Andrae, M. y Schimrick, M., op. cit., nota 21, p. 645; Franzina, P., Kramer, X. y Fitchen, J., op. cit., nota 21, p. 504. También niegan ese carácter vinculante del certificado, si se contradice con la resolución judicial de base, Wautelet, P., «Article 37», en Magnus, U. y Mankowski, P., European Commentaries on Private International Law (ECPIL), Brussels I bis Regulation, vol. I, Colonia, Dr. Otto Schmidt, 2016, p. 827; REQUEJo IsIDRo, M., op. cit., nota 11, p. 58. 
12. En todos los casos la certificación solo tendrá efectos dentro de los límites del carácter ejecutivo de la sentencia ${ }^{47}$. A tales efectos es muy útil el modelo de certificado negativo previsto en el art. 6.2 del Reglamento núm. 805/2004, que permitirá paralizar la ejecución por falta de fuerza ejecutiva de la decisión en origen. En el resto de los casos, dado que los certificados pueden pedirse a instancia de cualquiera de las partes, sería un instrumento que podría utilizar el deudor para oponerse a la ejecución, en la medida en que quedara constancia de tal extremo en dicho documento ${ }^{48}$.

\subsubsection{Requisitos de traducción}

13. Con carácter general, no se exige la traducción de documentos como presupuesto para el inicio del procedimiento de ejecución. En los modelos que parten del exequátur, queda a criterio del tribunal la exigencia de traducción ${ }^{49}$. En los modelos de fuerza ejecutiva directa, la exigencia de la traducción asume un carácter excepcional cuando se pide de oficio, pero se está convirtiendo en regla cuando es el demandado quien la solicita. Con ello se pretende facilitar y garantizar la impugnación de la resolución por el deudor ejecutado.

La traducción de los certificados a la lengua oficial (o una de las lenguas oficiales) del Estado requerido solo resulta exigible, de oficio, «si ha lugar» 50 o "en caso de que sea necesario» ${ }^{51}$. Únicamente se establece como preceptiva la traducción de algunos aspectos de los certificados de títulos ejecutivos europeos sobre menores ${ }^{52}$. No obstante, la normativa de desarrollo española ha ido más allá, sin dejar al juez margen de discrecionalidad en este punto, automatizado la obligación de traducción de manera dudosamente compatible con el tenor reglamentario ${ }^{53}$.

47 Cfr. art. 11 del Reglamento núm. 805/2004, con el comentario de PABST, S., «Article 11», en RAUSCHER, Th., Europäisches Zivilprozessrecht- und Kollisionsrecht (EuZPR/EuIPR) Kommentar, vol. I, 4. ${ }^{a}$ ed., Colonia, Dr. Otto Schmidt, 2016, nota 47, pp. 115-116; también ANDRAE, M. y ScHIMRICK, M., op. cit., nota 21, p. 654. En el mismo sentido, véase el art. 44 del Reglamento Bruselas II bis, en relación con los títulos ejecutivos europeos en materia de derechos de visita y restitución de menores (MAGNus, U., "Article 44», en Magnus, U. y MankowsKi, P., European Commentaries on Private International Law, Brussels II bis Regulation, Munich, Sellier, 2012, p. 372).

48 Por ejemplo, véase el Anexo I del Reglamento Bruselas I bis, apartado 4.4; o el Anexo II del Reglamento Bruselas II bis, apartado 9.1 del cuestionario. Véase PABST, S., op. cit., nota 47, p. 115.

49 Así puede comprobarse respecto de Bruselas II bis (art. 38), del Reglamento núm. 4/2009 (art. 47.2), del Reglamento núm. 2016/1103 (art. 46.2) y del Reglamento núm. 2016/1104 (art. 46.2 ).

${ }^{50}$ Véase el art. 42.3 del Reglamento Bruselas I bis y el art. 20.1.d) del Reglamento núm. 4/2009.

51 Así se prevé en el art. 20.1.c) del Reglamento núm. 805/2004; art. 21.1.b) del Reglamento núm. 1896/2006; y art. 21.2.b) del Reglamento núm. 861/2007.

52 El art. 45.2 de Bruselas II bis establece la obligación de traducción del apartado 12, para las modalidades del ejercicio del derecho de visita, y del apartado 14, para las medidas adoptadas para garantizar la restitución del menor.

53 Cfr. la DF 23, apartado 15 LEC, para los monitorios europeos, y la DF 24, apartado 9, para los procesos de escasa cuantía. Más acorde con el Reglamento es la discrecionalidad que se deja al órgano judicial en el marco de Bruselas I bis (véase la DF 25, apdo. 2.2). 
En relación con la resolución judicial, no está prevista la traducción para el caso del título ejecutivo europeo del Reglamento núm. 805/2004, considerando que el documento importante es el certificado no la resolución ${ }^{54}$. Para el resto de los títulos, solo resultará exigible «si no puede continuar sus diligencias sin ella» 0 «en caso de que sea necesario» ${ }^{55}$. Habrá que entender, por ejemplo, que si la condena es dineraria, resultará más fácil de identificar y comprender el fallo que si la condena no es dineraria ${ }^{56}$.

14. Perspectiva diferente es la exigencia de traducción de la resolución de origen por parte del ejecutado. El Reglamento de alimentos ${ }^{57}$ obliga a realizar dicha traducción si así lo pide el demandado. Bruselas I bis refuerza aún más la posición del deudor ${ }^{58}$, determinando incluso una suspensión de la ejecución. Ante tal eventualidad, el acreedor o bien traduce desde el principio la resolución ${ }^{59} \mathrm{o}$ bien solicita medidas cautelares (con base en los arts. $40 \mathrm{o}$ 43.2) para limitar el impacto de una posible suspensión del procedimiento de ejecución.

Llama en este caso poderosamente la atención los diferentes estándares de defensa del deudor que, en el caso de los alimentos o en el ámbito de Bruselas I bis puede exigir esa traducción, mientras que en el caso de los títulos ejecutivos europeos ni siquiera está prevista la traducción de la resolución de base. Si la finalidad de la traducción es facilitar la impugnación de la ejecución, esta debería facilitarse en todo caso dado que la propia resolución puede contener aspectos de fondo no incluidos en la certificación ${ }^{60}$.

\subsubsection{Notificaciones y despacho de ejecución}

15. El despacho de ejecución de las resoluciones firmes solo podrá producirse pasados veinte días desde la firmeza de la resolución (art. 548 LEC), periodo que tiene por finalidad habilitar un plazo de cumplimiento voluntario de la sentencia por parte del deudor. Evidentemente, se presupone en este caso una notificación previa de la resolución condenatoria que, en nuestro Derecho procesal, resulta preceptiva (arts. 150.1 y 497.2 LEC). A partir de

54 GASCón Inchausti, F., op. cit., nota 25, p. 182.

55 Véase el art. 42.4 de Bruselas I bis; art. 21.2.b) del Reglamento núm. 1896/2006; fórmula parecida se utiliza en el art. 38.2 de Bruselas II bis, art. 47.2 del Reglamento núm. 650/2012; y arts. 46.2 de los Reglamentos núms. 2016/1103 y 2016/1104.

56 Cfr. Gascón Inchausti, F., «La reconnaissance et l'exécution des décisions dans le règlement Bruxelles I bis», en GuINCHARD, E. (dir.), Le nouveau règlement Bruxelles I bis, Bruselas, Bruylant, 2014, pp. 205 y ss., esp. p. 228.

57 Arts. 20.2 y 28.2 del Reglamento núm. 4/2009.

58 Art. 43.2 de Bruselas I bis. La misma estela sigue el art. 35 de la Propuesta de reforma de Bruselas II bis [Documento COM (2016) 411 final].

59 En este sentido, Gascón InCHausti, F., op. cit., nota 56, p. 237. Con esa aportación, el acreedor cubre también un eventual requerimiento de traducción por parte de la autoridad de la ejecución, al amparo del art. 42.4 de Bruselas I bis.

60 Véase párr. 30. 
ahí, el despacho de ejecución podrá conllevar, con carácter inmediato y sin oír al deudor, la orden de medidas ejecutivas concretas ${ }^{61}$.

En el caso de la ejecución transfronteriza, la notificación de la resolución condenatoria, previa al inicio de la ejecución forzosa, no está expresamente garantizada en los Reglamentos europeos, con la excepción de Bruselas I bis y de Bruselas II bis. En efecto, de una parte, el carácter ejecutivo de una resolución y, en su caso, la necesidad de la notificación de la resolución al deudor, dependen de la ley del Estado de origen; de otra parte, los certificados previstos en los Reglamentos no incorporan la información sobre si la notificación de la resolución se ha producido ${ }^{62}$. Es más, el propio contenido de ciertos certificados revela su posible emisión antes de la notificación de la sentencia ${ }^{63}$.

Cuando se requiere exequátur, el propio procedimiento de declaración de fuerza ejecutiva servirá para que el deudor tenga conocimiento de la fuerza ejecutiva de la decisión en España y el plazo de los veinte días de cumplimiento voluntario debe contarse desde que la resolución sea título ejecutivo en España. En este contexto, es criticable el art. 32 del Reglamento Bruselas II bis, que obliga a notificar la resolución sobre la declaración de fuerza ejecutiva solo al solicitante de la ejecución, sin decir nada sobre la notificación a la persona frente a la que se dirige la ejecución ${ }^{64}$.

16. Cuando se parte de la fuerza ejecutiva directa, el deudor puede encontrarse en peor situación, dado que puede tener conocimiento de la resolución y del certificado en el momento del despacho de ejecución, sin tener asegurada la notificación previa. En este contexto, Bruselas I bis ocupa una posición especial al exigir la notificación del certificado antes de la adopción de cualquier medida ejecutiva (art. 43.1) ${ }^{65}$. Se entiende implícitamente, por

61 Véase el art. 554 en relación con el art. 551 LEC.

${ }^{62}$ Curiosamente el art. 47.1 del Convenio de Bruselas de 1968 sí exigía la acreditación de la notificación de la resolución, exigencia que se basaba precisamente en su conocimiento efectivo por parte del deudor para su cumplimiento voluntario (informe de JENARD, P., DOCE C núm. 189, de julio de 1990).

${ }^{63}$ Así, el art. 43.1 de Bruselas I bis obliga a la notificación del certificado de manera conjunta con la sentencia, si antes no se hubiera notificado esta; a sensu contrario, cabe una emisión del certificado sin notificación previa de la resolución. Esto explica también que en el Anexo I, apartado 4.5, del Reglamento Bruselas I bis se pregunte si en el momento de la emisión del certificado se había ya notificado la sentencia y, en su caso, en qué lengua. Véase la Sentencia de la AP de Valladolid (Sección 3.a) núm. 284/2016, de 19 de octubre (JUR 2016/253689), donde la acreditación, entre otras cosas, de la notificación de la resolución de origen se entendió que desvirtuaba las alegaciones de indefensión en origen.

${ }^{64}$ En todo caso, en Bruselas II bis es presupuesto para la ejecución la notificación previa de la resolución al demandado (art. 28) y el certificado del art. 39 de Bruselas II bis, en relación con el Anexo II, incorpora la información sobre tal extremo (apdo. 9.2).

65 La notificación del certificado, como trámite independiente, rompe con el principio de equivalencia o asimilación a los títulos nacionales (CUNIBERTI, G. y RUEDA, I., op. cit., nota 21, p. 858; FRANzina, P., Kramer, X. y Fitchen, J., op. cit., nota 21, p. 501). Aunque se ha dicho que el art. 42.2 de Bruselas I es antecedente el art. 43.1 de Bruselas I bis, su función nada tienen nada que ver, dado que en el primer caso se ubica dentro del procedimiento "contradictorio» de exequátur, que obliga a su notificación para un eventual recurso, mientras que en Bruselas I bis, no hay posibilidad de recurrir la 
razones sistemáticas, que dicha notificación depende de la autoridad del Estado de la ejecución si no se hubiera realizado anteriormente en el Estado de origen ${ }^{66}$. Esa misma notificación previa vuelve a encontrarse en el certificado de medidas de protección civil del Reglamento (UE) núm. 606/2013, pero que, en este caso, debe realizar la autoridad del Estado de origen ${ }^{67}$. Y esta tendencia se confirma en la Propuesta de reforma de Bruselas II bis ${ }^{68}$.

Se ha criticado tal previsión por su dudosa eficacia práctica, en la medida en que el deudor no sea advertido concretamente ante qué Estado se va a iniciar la ejecución ${ }^{69}$, y por sobreprotección del deudor, limitando el efecto sorpresa de la ejecución y sin conocer las consecuencias procesales de omitir esta notificación ${ }^{70}$. Su principal ventaja es que se garantiza la notificación previa de la resolución, si esta no se hubiera producido ya, para permitir el cumplimiento voluntario de la misma. No obstante, esta finalidad se ve comprometida con la normativa de desarrollo española, dado que la DF 25 de la LEC prevé la notificación conjunta del certificado con la del despacho de ejecución, lo que permite la ordenación de determinadas medidas (como las de localización y averiguación de bienes) sin esperar a la notificación previa al deudor ${ }^{71}$.

No existe una previsión semejante para otros títulos ejecutivos directos, tales como las resoluciones de alimentos y los títulos ejecutivos europeos. No se alcanza a comprender estos diferentes estándares de protección del deudor, dado que en todos los casos el deudor debería tener igualdad de oportunidades con vistas al cumplimiento voluntario de la sentencia. Además, en estos supuestos, la ausencia de notificación previa del certificado no solo impide garantizar el cumplimiento voluntario de la resolución, sino que limita la posibilidad de «impugnar» el título en el Estado de origen antes del inicio del procedimiento de ejecución en el Estado requerido ${ }^{72}$. La efectividad de

emisión del certificado. La misma función que tenía el art. 42.2 de Bruselas I la cumple en este caso el art. 49.2 del Reglamento núm. 650/2012 y arts. 48.2 de los Reglamentos núms. 2016/1103 y 2016/1104.

66 Una notificación previa del certificado instada por el acreedor en el Estado de origen supliría esta notificación y no sería necesario redundar en ella, cfr. GASCón INCHAUSTI, F., op. cit., nota 56, p. 232.

67 Art. 8.1 del Reglamento núm. 606/2013, del Parlamento Europeo y del Consejo, de 12 de junio, relativo al reconocimiento mutuo de medidas de protección en materia civil ( $D O$ L núm. 181, de 29 de junio de 2013).

68 Art. 35 de la Propuesta [Documento $\operatorname{COM}(2016) 411$ final].

69 Así lo subrayan Cuniberti, G. y RuedA, I. (op. cit., nota 21, p. 858), lo que solo se arreglaría si la notificación se hiciera en el Estado de la ejecución (MANKowsKI, P., "Art. 43 Brüssel Ia-VO", en RAUSCHER, Th., Europäisches Zivilprozessrecht- und Kollisionsrecht (EuZPR/EuIPR) Kommentar, vol. I,

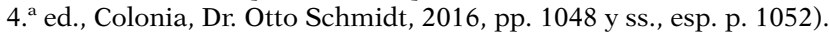

${ }^{70}$ Por ejemplo, es dudosa la nulidad de la ejecución por vulnerar derechos de defensa porque es dudosa la existencia de un derecho fundamental a ser informado de cualquier documento emitido en un proceso del cual se es parte, GASCÓN InCHAUSTI, F., op. cit., nota 56, pp. 234-235.

71 Véase el art. 553 LEC en relación con el art. 554 LEC.

72 Se trata de las vías de rectificación o revocación del certificado del art. 10, o la impugnación de la resolución del art. 19, ambos del Reglamento núm. 805/2004. GAScón INCHAUSTI, F. (op. cit., nota 25, pp. 160-161) subraya que la garantía de estos recursos requiere un conocimiento previo por parte del deudor, aunque la notificación no esté prevista en el Reglamento. En la misma situación se encontraría la solicitud de reexamen de las resoluciones de alimentos (art. 19 del Reglamento núm. 4/2009). 
estos recursos quedaría postergada al despacho de ejecución si con anterioridad el deudor no tuvo conocimiento de la resolución.

\subsection{Régimen de las medidas cautelares}

\subsubsection{Medidas cautelares dictadas por el tribunal de origen}

17. La ejecución transfronteriza de medidas cautelares dictadas por el tribunal de otro Estado está supeditada a que hayan sido dictadas por los tribunales competentes sobre el fondo ${ }^{73}$ y que, además, en caso de medidas dictadas inaudita parte, la resolución se haya notificado con carácter previo a la ejecución. Tales exigencias derivan de una interpretación sistemática del art. 2.a) y del contenido del certificado previsto en el art. 42.2.b) de Bruselas I bis. Las medidas cautelares y provisionales que incumplieran tales condiciones no entrarían directamente dentro del concepto de resolución y, en caso de despacho de ejecución, el deudor podría oponer la nulidad del mismo ${ }^{74}$. Una respuesta diferente se ofrece para el caso de la orden europea de retención de cuentas, dado que expresamente establece una vía de ejecución de una medida cautelar dictada inaudita parte ${ }^{75}$, destinada a garantizar el efecto sorpresa incluso tratándose de una ejecución transfronteriza. También en este caso se prevé un control de la competencia, aunque se articularía ante los tribunales del Estado de origen, como motivo de impugnación del título ${ }^{76}$.

Curiosamente, el resto de los instrumentos europeos no contienen ninguna previsión expresa que otorgue un tratamiento singular a la ejecución transfronteriza de las medidas cautelares. El silencio normativo no parece que pueda justificar un posicionamiento distinto del Reglamento Bruselas II bis o del Reglamento de alimentos. Ambas condiciones (notificación previa y competencia sobre el fondo) deberían considerarse como condiciones uniformes apelando a un criterio compartido mínimo entre todos los Reglamentos ${ }^{77}$.

\footnotetext{
${ }^{73}$ No serviría a estos efectos una competencia basada en el art. 35 de Bruselas I bis o en el art. 20 de Bruselas II bis.

${ }_{74}$ Véase párr. 29. En consecuencia, tales medidas no serían ejecutables en virtud del Reglamento aunque sí podrían serlo conforme al Derecho nacional, conforme indica el considerando 33 del Reglamento.

75 Véase el art. 11 del Reglamento (UE) núm. 655/2014, del Parlamento Europeo y del Consejo, de 15 de mayo, por el que se establece el procedimiento relativo a la orden europea de retención de cuentas a fin de simplificar el cobro transfronterizo de deudas en materia civil y mercantil (DO núm. L 189, de 27 de junio de 2014); al respecto, véase Jiménez Blanco, P., «La Orden Europea de Retención de Cuentas: avances y limitaciones», AEDIPr, vols. XIV-XV, 2014-2015, pp. 243 y ss.

76 Véase el art. 33 del Reglamento núm. 655/2014.

77 Así se defiende por Rauscher, Th., "Art. 3 Brüssel IIa-VO», en Rauscher, Th. (coord.), Euro-

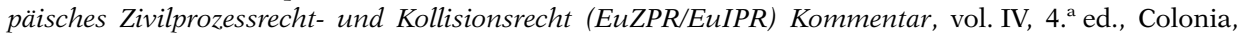
Dr. Otto Schmidt, 2016, pp. 70 y ss., esp. p. 67, extrapolando a Bruselas II bis la jurisprudencia del TJCE Denilauer (asunto 125/79, ECLI:EU:C:1980:130). En este contexto, también debe considerarse la STJUE Purrucker (asunto C-296/10, ECLI:EU:C:2010:665), que habilita a cierto control de la compe-
} 


\subsubsection{Medidas cautelares dictadas por el tribunal de ejecución}

18. En el Derecho procesal español, carece de utilidad práctica solicitar medidas cautelares para la ejecución de títulos nacionales, dado que el despacho de ejecución conlleva la adopción de medidas ejecutivas (el embargo de la cuenta, conforme a los arts. 549, 551 y 621 LEC). Sin embargo, las medidas cautelares resultan fundamentales en los procedimientos de ejecución transfronteriza de una resolución, antes del inicio de la ejecución propiamente dicha, para garantizar el efecto sorpresa de la ejecución, y evitar la desaparición de bienes del deudor. También pueden resultar fundamentales durante el procedimiento de ejecución, en el caso de que haya una impugnación del título en el Estado de origen.

19. Antes de tener título ejecutivo en España, cuando se requiere exequátur, son necesarias las medidas cautelares mientras se tramita la declaración de fuerza ejecutiva, dada la dilación que puede seguir este procedimiento. En este caso, deberán aplicarse las condiciones exigidas por el Derecho español en torno al fumus bonus iura y el periculum in mora o la necesidad de prestar caución ${ }^{78}$. Obtenida la declaración de fuerza ejecutiva, esta ya será base suficiente para la adopción de medidas cautelares, por lo que deberá prescindirse de los preceptos procesales nacionales relativos a su concesión, entre ellos el que exige fianza ${ }^{79}$. Es llamativo el silencio de Bruselas II bis en este punto, debiendo colmarse tal laguna, en vez de remitiéndose al Derecho procesal del Estado de la ejecución, aplicando analógicamente la solución compartida que tienen el resto de los instrumentos europeos.

En los supuestos de títulos con fuerza ejecutiva directa en España, ese mismo título supone ya la autorización para adoptar medidas cautelares, sin tener que supeditarse tampoco a las condiciones exigidas por nuestro legislador ${ }^{80}$. En el ámbito Bruselas I bis, la solicitud de estas medidas cautelares (art. 40), antes de la ejecución, resulta especialmente aconsejable para el acreedor dado que va a tener que notificar el certificado al deudor y, en

tencia del tribunal que dicta medidas cautelares o provisionales. En este contexto, cabe considerar el art. 48 de la Propuesta de revisión de Bruselas II bis [Documento COM(2016) 411 final].

78 Encajaría ahí la previsión del art. 54.1 del Reglamento núm. 650/2012, del art. 36 del Reglamento núm. 4/2009; y arts. 53.1 de los Reglamentos núms. 2016/1103 y 2016/1104. Para valorar el fumus bonus iura, habrá que considerar la posibilidad de reconocimiento de la sentencia en España.

79 Así se venían interpretando los apartados 1 y 2 del art. 47 de Bruselas I, entendiendo que en el segundo caso la autorización para adoptar medidas cautelares deriva directamente del Reglamento. Cfr. Palsson, L., "Article 47», en Magnus, U. y Mankowski, P. (eds.), European Commentaries on Private International Law. Brussels I Regulation, Münich, Sellier, 2007, pp. 678-679; Hess, B. Europäisches Zivilprozessrecht, Heidelberg, C. F. Müller, 2010, p. 363; Franzina, P., Kramer, X. y Fitchen, J., op. cit., nota 21, p. 414. Véase el Auto de la AP Barcelona (Sección 15. ${ }^{\text {) }}$, de 4 de marzo de 2004 (AC 2004/1550), en relación con la inexigibilidad de la fianza como presupuesto para la medida cautelar. Encajaría aquí también la previsión del art. 54.2 del Reglamento núm. 650/2012, art. 36.2 del Reglamento núm. 4/2009, y arts. 53.2 de los Reglamentos núms. 2016/1103 y 2016/1104.

${ }^{80}$ Así debe interpretarse el art. 40 de Bruselas I bis; véase GAScón IncHAusTi, F., op. cit., nota 56, p. 230; también lo insinúa, ReQueJo Isidro, M., op. cit., nota 11, pp. 53-54. Claramente se deriva de la DF 25, apartado 2, regla 4. ${ }^{a}$ LEC. Una regla similar se encuentra en el art. 18 del Reglamento núm. 4/2009. 
su caso, traducir la resolución, antes de que puedan adoptarse medidas de ejecución ${ }^{81}$. En todo caso, el contenido y tipo de medidas concretas que puedan solicitarse son las establecidas en el Derecho nacional del Estado de la ejecución. Deben «adaptarse» a la ejecución transfronteriza en este caso las medidas cautelares previstas en los arts. 721 y ss. LEC, dado que las medidas ejecutivas previstas en art. 621 y ss. son accesorias a medidas ejecutivas ya decretadas. A las medidas nacionales, debe añadirse la orden europea de retención de cuentas, aplicable a los litigios transfronterizos que entran dentro de Bruselas I bis y del Reglamento de alimentos. La complementariedad entre instrumentos justificaría, asimismo, el uso de la base jurídica del art. 40 de Bruselas I bis para permitir la adopción de medidas cautelares antes de la ejecución de un título ejecutivo europeo ${ }^{82}$.

20. Finalmente, se encuentran las medidas cautelares que pueden adoptarse cuando el título ejecutivo sea objeto de impugnación en el Estado de origen (contexto del art. 23 del Reglamento núm. 805/2004) o en el marco del procedimiento de ejecución en el Estado requerido cuando se solicite la denegación de la misma [contexto del art. 44.1.a) de Bruselas I bis] ${ }^{83}$. La adopción de medidas cautelares no es automática, sino que debe instarse por el deudor ejecutado y será valorada por el juez junto con las medidas de suspensión del procedimiento o la constitución de garantías para la ejecución, sin que puedan entenderse como excluyentes entre sí ${ }^{84}$. Esta posibilidad de medidas cautelares debería extrapolarse al ámbito del Reglamento de alimentos, cuando, en el marco del art. 19, se solicite un reexamen de la resolución en el Estado de origen ${ }^{85}$.

Las posibilidades que otorga el art. 44 Bruselas I bis o el art. 23 Reglamento núm. 805/2004 se deciden por el órgano competente del Estado requerido, en el marco del procedimiento de ejecución. Tal supuesto debe diferenciarse del caso de una suspensión o limitación de la fuerza ejecutiva en origen y que la propia autoridad de origen hubiera decretado medidas cautelares o la constitución de una garantía ${ }^{86}$. En tal caso, lo único que vincula al órgano

81 Recuérdese el art. 43 Bruselas I bis. Véase la DF 25, apartado 3, regla 4. ${ }^{a}$ LEC.

82 Caso del art. 47.1 Bruselas I en relación con el Reglamento núm. 805/2004 (GAScón Inchausti, F., op. cit., nota 25, pp. 163-164) que ahora habrá que entender sustituido por el art. 40 Bruselas I bis.

${ }^{83}$ Dado que tales medidas ya se solicitarán producido el despacho de ejecución, debe entenderse que las medidas son las de los arts. 621 y ss. LEC, como garantía del embargo de bienes y derechos, sometidas a la exigencia de caución por parte del ejecutante en los términos del art. 561.3 LEC. No obstante, también se ha defendido una interpretación amplia que incluya asimismo las medidas del art. 727 LEC [MARTínez SANTos, A., «Artículo 44», en Blanco-Morales Limones, P. et al. (coords.), Comentario al Reglamento (UE) núm. 1215/2012 relativo a la competencia judicial, el reconocimiento y la ejecución de resoluciones judiciales en materia civil y mercantil, Navarra, Thomson Reuters/Aranzadi, 2016, pp. 833 y ss., esp. pp. 836-837].

${ }_{84}$ De hecho, lo habitual es que las medidas cautelares se decreten cuando se produce la suspensión del procedimiento; en otro caso, la ejecución provisional ya determinaría el alzamiento de las medidas cautelares acordadas y que estén en relación con dicha ejecución (art. 731.2 LEC).

${ }_{85}$ Véase que el art. 21.3 del Reglamento núm. 4/2009 solo recoge la posibilidad de suspensión de la ejecución, manteniendo silencio sobre la posibilidad de medidas cautelares.

${ }^{86}$ En el certificado emitido por las autoridades de origen puede hacerse constar que la ejecución queda temporalmente suspendida, limitada a medidas cautelares o condicionada a la constitución de una garantía todavía pendiente (apdo. 5.2 del certificado del Anexo IV del Reglamento núm. 805/2004). 
de ejecución es la suspensión de la fuerza ejecutiva, pero no el resto de las medidas acordadas a menos que se hubiere instado su ejecución en España.

\section{OPOSICIÓN Y SUSPENSIÓN DE LA EJECUCIÓN}

\subsection{Impugnación del título en el Estado de origen e incidencia en la ejecución}

21. En el ámbito de la ejecución transfronteriza, la defensa del deudor puede dirigirse (cuando sea posible) frente al título o frente a su ejecución, sobre la base de circunstancias sobrevenidas. El título podrá impugnarse, según los casos, exclusivamente en el Estado de origen (como ocurre en los títulos ejecutivos europeos y en las resoluciones de alimentos directamente ejecutivas) o en el Estado de la ejecución (a través del exequátur o de la denegación de la ejecución de Bruselas I bis). En el primer caso, una eventual revisión o revocación de la decisión en el Estado de origen tendrá un alcance transfronterizo, impidiendo su ejecución en cualquier Estado; en el segundo caso, simplemente deja sin efecto la ejecución en el ámbito territorial de ese Estado.

Salvo en el exequátur, la impugnación del título, en el Estado de origen o en el Estado de la ejecución, ni impide el inicio de la ejecución ni, con carácter general, obliga a suspenderla. No obstante, procede verificar los diferentes supuestos de impugnación del título en el Estado de origen y su incidencia en la ejecución. En el Estado de origen, el título puede ser objeto de un recurso ordinario (dada la posibilidad de ejecución de títulos no firmes) o de una «revisión» basada en una indefensión del deudor.

22. En el caso de un recurso ordinario en el Estado de origen (o se está aún en plazo para hacerlo), si se requiere exequátur, puede producirse un efecto suspensivo, a instancia de parte, de la declaración de fuerza ejecutiva. Así se establece para Bruselas II bis (art. 35). Sin embargo, en el resto de los títulos con exequátur y en el caso de los títulos ejecutivos directos, la mera interposición de un recurso en origen no determina un efecto suspensivo; solo en el caso de que dicho recurso suponga, conforme al Derecho del Estado de origen, una suspensión de la fuerza ejecutiva de la decisión en aquel Estado $^{87}$.

23. En caso de recursos de revisión, el deudor asume la carga de hacer valer su indefensión en el Estado de origen ${ }^{88}$. Aunque con diferentes denominaciones, todos implican un estándar similar de protección de los derechos de defensa. La interposición de tales recursos en el Estado de origen permite, de manera potestativa y a instancia del deudor, suspender la ejecución de resolu-

\footnotetext{
87 Véase párr. 4.

88 Art. 19 del Reglamento núm. 805/2004, art. 20 del Reglamento núm. 1896/2006, art. 19 del Reglamento núm. 861/2007 y art. 19 del Reglamento núm. 4/2009.
} 
ciones sobre alimentos (art. 21.3); en los títulos ejecutivos europeos, el efecto suspensivo tiene carácter excepcional frente a otras medidas como limitar la ejecución a medidas cautelares o subordinar la ejecución a la constitución de una garantía ${ }^{89}$. A la misma solución se llega cuando se solicita la rectificación o revocación del título ejecutivo europeo para créditos no impugnados. Un silencio sobre la posibilidad de suspensión existe para el caso de la rectificación de los certificados de título ejecutivo de los arts. 41 y 42 de Bruselas II bis, habiéndose optado en este caso por la aplicación general de la remisión a los Derechos nacionales en virtud del art. $47.1^{90}$. Sería más coherente, sin embargo, aplicar analógicamente las medidas del art. 23 del Reglamento (CE) núm. 805/2004 a todos los supuestos en que el título se impugne en origen.

La revocación o revisión de la resolución de origen determinará el fin del proceso de ejecución en el Estado requerido y en cualquier Estado en el que la ejecución se hubiera puesto en marcha. En el caso del Derecho español, procedería en estos casos una aplicación analógica del art. 534 LEC.

\subsection{Impugnación del título en el Estado de la ejecución}

24. La vía tradicional para impugnar el título en el Estado de la ejecución se encontraba en el procedimiento previo del exequátur, que se mantiene por el momento para los litigios sobre familia y sucesiones ${ }^{91}$. Esto obligaría al demandado a articular de manera separada, y sucesiva, los motivos de oposición a la eficacia del título en España (establecidos en los respectivos Reglamentos) y los motivos de oposición a la ejecución (previstos en el Derecho nacional del Estado de la ejecución ${ }^{92}$. Ninguna medida ejecutiva será posible mientras se esté tramitando la decisión sobre el exequátur, a excepción de las medidas cautelares ${ }^{93}$.

25. En el ámbito de Bruselas I bis, puede solicitarse la denegación de la ejecución impugnando el título en el Estado de la ejecución, pero la oposición por el deudor no va a impedir la adopción de actos ejecutivos ${ }^{94}$ y la

89 Art. 23 del Reglamento núm. 805/2004, art. 23 del Reglamento núm. 1896/2006 y art. 23 del Reglamento núm. 861/2007.

90 Rauscher, Th., "Art. 43 Brüssel IIa-VO», en Rauscher, Th. (coord.), Europäisches Zivilprozess-

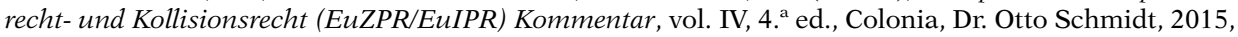
pp. 354 y ss., esp. p. 356.

91 Téngase en cuenta que la Propuesta de revisión de Bruselas II bis incorpora también la supresión del exequátur.

92 En el Auto de la AP Las Palmas (Sección 5. a), de 30 de marzo de 2009 (JUR 2009/247649) se invocó por el deudor la nulidad radical del despacho de ejecución de una sentencia portuguesa por defectuosa notificación a través de correo y falta de traducción, concluyendo el tribunal español que tal oposición debía desestimarse por inexistencia de infracción del Reglamento (CE) núm. 1348/2000, de 29 de mayo. La cuestión es que tal motivo no debió ser analizado en la fase de la ejecución forzosa, sino solo en la fase previa del exequátur en ese caso exigible por el Reglamento Bruselas I.

93 Véase párr. 19, en relación con su extensión también a Bruselas II bis.

94 El plazo para solicitar dicha denegación es a partir de la notificación del despacho de ejecución (DF 25, apdo. 4, LEC), pero no existe garantía para el ejecutado de poder oponerse a la ejecución antes de que sean dictados actos ejecutivos concretos. 
ejecución continuará su curso salvo que el juez valore, a petición del deudor, su suspensión, que esta se limite a medidas cautelares o que se condicione a la constitución de determinadas garantías (art. 44). En este caso, la suspensión del procedimiento de ejecución será excepcional en los términos de la legislación procesal española ${ }^{95}$. Para salvaguardar su derecho, recuérdese que el acreedor puede solicitar medidas cautelares incluso antes del inicio de la ejecución (art. 40).

Formalmente, cabe diferenciar entre los motivos de denegación de la ejecución basados en el título, previstos en el art. 45 de Bruselas I bis, y los basados en la ejecución, previstos en el Derecho nacional. No obstante, el considerando 30 de Bruselas I bis establece la invocación de todos los motivos, al margen de su origen, en el mismo procedimiento y en esta clave debería interpretarse la remisión al Derecho nacional del art. 41 del Reglamento ${ }^{96}$. Sin embargo, en el Derecho español se articulan dos procedimientos: la impugnación del título con base en el art. 45 se tramita conforme al juicio verbal ${ }^{97}$ y los motivos de oposición nacionales por la vía de los arts. 556 y ss. LEC. En la práctica, hay una coincidencia sustancial en el plazo para articular la oposición y en las fases del procedimiento, aunque solo la impugnación por los motivos del art. 45 podrá llegar a un recurso extraordinario por infracción procesal o de casación ${ }^{98}$. Esta separación impide, por tanto, una total integración en el mismo procedimiento de los diferentes motivos de oposición a la ejecución.

\subsection{La oposición a la ejecución}

26. La eliminación del exequátur y la introducción del sistema de fuerza ejecutiva directa no afecta al número y tipo de causas de oposición a la ejecución previstas en el Derecho español ${ }^{99}$, que siguen siendo aplicables por el principio de asimilación a las resoluciones nacionales, siempre que no sean incompatibles con los motivos previstos en los Reglamentos ${ }^{100}$. Solo la Propuesta de revisión de Bruselas II bis pretende ir más allá, introduciendo causas de oposición a la ejecución uniformes en la propia norma reglamen-

95 De los arts. 561.3 y 566 LEC se deriva el carácter excepcional de la suspensión del procedimiento de ejecución (ReQuejo Isidro, M., op. cit., nota 11, p. 77; y MarTínez SANTOS, A., op. cit., nota 83, pp. 838-839).

96 DomeJ, T., «Die Neufassung der EuGVVO (Quantensprünge im europäischen Zivilprozessrecht)», Rabels Z., vol. 78, 2014, pp. 598 y ss., esp. p. 515; MANKowSKI, P., op. cit., nota 28, p. 1029. Véase otra posición en Gascón Inchausti, F., op. cit., nota 56, p. 243.

97 Véase la DF 25, apartado 4 LEC.

98 Cfr. Requejo Isidro, M., op. cit., nota 11, p. 77. Así se constata con los arts. 49 y 50 de Bruselas I bis, en relación con la DF 25 , apartado 4, regla 6. ${ }^{a}$, LEC.

${ }_{99}$ Los arts. 556 y ss. LEC para la ejecución definitiva y el art. 528 LEC para la ejecución provisional.

100 Cfr. los considerandos 30 del Reglamento núm. 4/2009 y de Bruselas I bis y el art. 41.2 de este último; la DF 23, apartado 14 LEC, en relación con el monitorio europeo; y la DF 24, apartado 8 LEC en relación con el escasa cuantía. 
taria ${ }^{101}$. En todo caso, ninguno de los motivos de oposición a la ejecución puede implicar ni una revisión de fondo de la resolución judicial de origen ni un cauce encubierto para controlar las condiciones de emisión del certificado del título ejecutivo europeo que, como hemos visto, debe realizarse en el Estado de origen. En este sentido, resultan fundamentales la regla de la prohibición de discriminación en los controles por origen del título (nacional o de otro Estado miembro) y la regla de la preclusión de las circunstancias alegables (solo podrán invocarse frente a la ejecución circunstancias sobrevenidas posteriores al título que no pudieron ser alegadas en el proceso de origen).

27. Al margen de las causas de oposición nacionales, un motivo de oposición que aparece siempre recogido en los Reglamentos es el carácter inconciliable de la decisión con otra decisión sobre el mismo objeto y las mismas partes, ya sea del foro o reconocible en el foro pero procedente de otro Estado. Tal motivo de oposición solo podrá invocarse en la fase de ejecución forzosa si no pudo invocarse con anterioridad en el Estado de origen o, en su caso, en la fase de exequátur. Es llamativo que tal preclusión solo se prevea expresamente en relación con el Reglamento núm. 805/2004 ${ }^{102}$, y no aparezca en Bruselas I bis o en el Reglamento de alimentos. No obstante, cabe entender que es un mínimo que subyace en todo caso, dado que lo contrario supondría una revisión de fondo del título ejecutivo ${ }^{103}$. Aparte quedan los supuestos de resoluciones sobre alimentos o responsabilidad parental, que carecen de efecto de cosa juzgada material, inconciliables con resoluciones posteriores ${ }^{104}$.

28. En el ámbito del Derecho nacional, el deudor puede oponerse, invocando como motivos de fondo, el pago o cumplimiento de lo ordenado en la sentencia, la caducidad de la acción ejecutiva y las transacciones para evitar la ejecución, siempre que consten en documento público (art. 556 LEC). Al margen de la, ya analizada, particularidad de la caducidad de la acción ejecutiva, la compatibilidad del resto de motivos de fondo con los instrumentos europeos se da siempre que las circunstancias invocadas, como sería el pago, se hayan producido después de la emisión del título en el Estado de origen; de lo contrario se estaría introduciendo, por esta vía, una verdadera revisión

101 En el texto proyectado, el art. 40.4 del Documento COM(2016) 411 final, excluye expresamente la invocación de motivos de ejecución distintos de los establecidos en el Reglamento.

102 La preclusión no afecta a aquellos supuestos en los que se invocó la inconciliabilidad en origen pero dicha alegación fue desestimada; por ejemplo, una decisión del tercer Estado que podría ser no reconocible en el Estado de origen pero sí en el Estado de la ejecución, cfr. GARCIMARTín ALFÉREZ, F. J., op. cit. , nota 31, pp. 184-185.

103 Esa misma preclusión se constata también en las alegaciones de indefensión en el proceso de origen: véase el art. 45.1.b) de Bruselas I bis.

104 Véase el art. 47.2 de Bruselas II bis, Jiménez Blanco, P., «La ejecución forzosa de las resoluciones de retorno en las sustracciones internacionales de menores», en ALDECOA LuZÁRRAGA, F. y ForNER Delaygua, J. (dirs.), La protección de los niños en el Derecho internacional y en las relaciones internacionales, Madrid, Marcial Pons, 2010, pp. 341 y ss., esp. pp. 358-360. En una clave semejante, véase el art. 21.2, párr. 3 del Reglamento núm. 4/2009. Interesantes son, en este contexto, las causas de denegación de la ejecución basadas en un cambio de circunstancias introducidas en la Propuesta de revisión de Bruselas II bis [art. 40 del Documento COM(2016) 411 final]. 
de fondo de la sentencia ${ }^{105}$. En este sentido, el pago posterior de la condena debería poder oponerse frente a la ejecución forzosa para todos los títulos, a pesar de su mención solo en alguno de los instrumentos ${ }^{106}$. Interesante es la opción, solo prevista en la actualidad para la orden europea de retención de cuentas, de poder invocar ese pago en el Estado de origen, dado que esta posibilidad desactivaría toda eficacia transfronteriza del título, sin tener que oponerlo ante las autoridades de cada Estado donde se pretendiera la ejecución del título ${ }^{107}$.

Estos motivos deben distinguirse de aquellos otros supuestos que requieren un pronunciamiento por parte del tribunal conforme el art. 564 LEC $^{108}$. Así ocurriría, por ejemplo, si los tribunales tuvieran que decidir sobre la compensación de un crédito en el marco de una ejecución. Ello exigirá una nueva demanda que se planteará ante el tribunal que tenga competencia judicial internacional para conocer del fondo. Si tal compensación tiene incidencia en la ejecución, deberá decidirse por los jueces españoles con base en su competencia exclusiva sobre la ejecución, pero esta no genera una vis atractiva para otorgar competencia a nuestros tribunales para un proceso declarativo ${ }^{109}$.

29. Entre los motivos de oposición procesal, puede incluirse la declinatoria por falta de jurisdicción o de competencia (ex art. 547, párr. 1 LEC), en la que podrá hacerse valer la falta de competencia objetiva o territorial para la ejecución. Dentro de la fase de oposición propiamente dicha, conforme al art. 559 LEC, pueden invocarse causas relativas a la falta de capacidad y representación de las partes ${ }^{110}$ y la nulidad radical del despacho de ejecución por no tener la resolución pronunciamientos de condena o no cumplir el documento presentado los requisitos exigidos para el despacho de ejecución (art. 559.1.3).

Especialmente cautelosos hay que ser con este último motivo, dado que no cabe alegar aquí cuestiones relativas a la regularidad del título de origen ${ }^{111}$. Sí podría hacerse valer la falta de exequátur de la decisión extranjera, si este

105 Cfr. el Auto AP de A Coruña (Sección 5. ${ }^{\text {a) }}$, de 26 de octubre de 2011, JUR 2012/8481.

106 Solo se recoge expresamente en el art. 22.2 del Reglamento núm. 1896/2006, y se menciona en el considerando 30 del Reglamento núm. 4/2009.

107 Véase el art. 33.1.e) del Reglamento núm. 655/2014.

108 Véase la posición crítica sobre aplicación de este precepto en el marco del art. 41.2 de Bruselas I bis, en REQUeJo IsIDRo, M. (op. cit., nota 11, p. 69). Véase en un contexto parecido el $\S 767$ ZPO alemana, BITTMANN, D. Ch., «Die Zulässigkeit materiell rechtlicher Einwendungen gegen einen Europäischen Vollstreckungstitel im Vollstreckungsstaat», IPRAx., 2015, pp. 129-134.

109 Cfr. la STJCE en el asunto C-220/84 (AS-Autoteile Service/Malhé, ECLI:EU:C:1985:302).

110 Véase en el Auto de la AP de Málaga (Sección 6. ${ }^{\text {a)}}$, de 20 de septiembre de 2000 (JUR 2001/75705), un ejemplo de oposición a la ejecución de una decisión extranjera por falta de acreditación de la identidad entre la entidad condenada por las resoluciones extranjeras y contra la que se pretende ejecutar la misma en España.

111 Claramente considera esta limitación el Auto de la AP de Pontevedra (Sección 6. ${ }^{\text {a) }}$, de 26 de septiembre de 2011 (AC 2011/2194). En el Auto de la AP de Guipúzcoa (Sección 3. ) $^{\text {) de }} 5$ de febrero de 2008 (JUR 2008/174407), frente a la alegación de la irregularidad en la emisión del certificado, la Audiencia entró indebidamente a valorar cómo se había realizado la notificación del proceso en origen, aspecto que debió entenderse acreditado con el certificado emitido. 
fuera preceptivo. También sería válida la oposición si no se hubiera aportado a la demanda ejecutiva la resolución de origen y el certificado (cuando este sea insubsanable). Asimismo, es el cauce para denunciar la falta la notificación previa del certificado o la traducción de la resolución, cuando estas sean presupuesto para la ejecución (como ocurre con el art. 43 de Bruselas I bis). También podrá oponerse la falta de fuerza ejecutiva de la decisión en origen si en el certificado no se hizo constar o la suspensión de la fuerza ejecutiva de la resolución en origen. El deudor ejecutado podrá acreditar la falta de fuerza ejecutiva por cualquier medio, excepto cuando se trata de certificados de títulos ejecutivos europeos de carácter constitutivo, dado que, debido a su carácter vinculante, solo podrán ser desvirtuados con el certificado negativo establecido reglamentariamente ${ }^{112}$. También esta sería la vía para oponerse a la ejecución de una medida cautelar si no se acredita, a través del certificado del art. 42.2 de Bruselas I bis, que se haya notificado la resolución al demandado y se haya dictado por un tribunal competente sobre el fondo, lo que habilita a un control implícito de la competencia en este caso.

30. Finalmente, pueden impugnarse los actos ejecutivos concretos contrarios a Derecho, cuando se haya producido una infracción de las normas que regulan los actos concretos del proceso de ejecución (art. 562 LEC) o cuando los actos de ejecución sean contradictorios con el título ejecutivo judicial (art. 563 LEC). Entrarían aquí supuestos en los que se hubiera trabado embargo sobre bienes inembargables, se pretende una ejecución a persona distinta de la que figura en la resolución, o se insta una ejecución de manera solidaria, cuando es obligación mancomunada. A los efectos de este examen de compatibilidad de la ejecución con el título, debe considerarse como título ejecutivo no solo el certificado, sino la propia resolución de base que siempre debe ser aportada al proceso y en la que pueden constar extremos no recogidos en el certificado ${ }^{113}$. De ahí la importancia de considerar también en este caso la traducción de la resolución de base ${ }^{114}$.

Cabría asimismo invocar en este ámbito un eventual recurso frente a la adaptación, realizada de oficio por el juez, en relación con una medida no conocida en el ordenamiento español ${ }^{115}$. Se intenta garantizar un equilibrio entre la extensión de los efectos de la decisión extranjera con el principio de

112 Recuérdese el Anexo IV del Reglamento núm. 805/2004.

113 Gascón InCHausti, F. (op. cit., nota 25, p. 184) pone precisamente el ejemplo de una decisión que establece una obligación mancomunada, sin que conste este dato en el certificado.

114 Véase párr. 14.

115 Sabido Rodríguez, M., "Artículo 54», en Blanco-Morales Limones, P. et al. (coords.), Comentario al Reglamento (UE) núm. 1215/2012 relativo a la competencia judicial, el reconocimiento y la ejecución de resoluciones judiciales en materia civil y mercantil, Navarra, Thomson Reuters/Aranzadi, 2016 , pp. 934-935. La adaptación se recoge expresamente en el art. 54 de Bruselas I bis y en el apartado 6 de la DF 25 LEC; asimismo, en el art. 11 del Reglamento (UE) núm. 606/2013. Un antecedente inmediato lo encontramos en el asunto DHL Express France (asunto C-235/09; ECLI:EU:C:2011:238, cdo. 56) que permite, en caso de desconocimiento en el Derecho del Estado requerido de la medida coercitiva dictada en el Estado de origen (en relación con las astreinte del Derecho francés), se adopte una medida propia del Derecho del Estado de ejecución destinada a garantizar, de forma equivalente, el cumplimiento de la prohibición judicial impuesta. 
asimilación y la viabilidad de la propia medida. El problema se dará obviamente cuando el Estado de la ejecución parta de numerus clausus para el reconocimiento o, en nuestro caso, para la adopción de medidas ejecutivas, en particular, en el ámbito registral o de derechos reales ${ }^{116}$, de las medidas cautelares ${ }^{117} \mathrm{o}$ de medidas coercitivas no dinerarias ${ }^{118}$.

\section{CONCLUSIONES}

31. De la comparación entre instrumentos y de sus principios informadores cabe derivar unas pautas que deberían utilizarse para la integración de lagunas y la elaboración de cuerpo mínimo uniforme en el ámbito de la ejecución forzosa. Entre estas pautas comunes cabe destacar:

- Las consecuencias que se derivan del principio de la extensión de los efectos y del concepto de fuerza ejecutiva de la resolución. De ello se deduce la aplicación de la ley del Estado de origen a la caducidad de la acción ejecutiva y la preceptiva suspensión de la ejecución en el Estado de la ejecución si se suspende o limita la fuerza ejecutiva de la resolución en el Estado de origen. Establecida la fuerza ejecutiva en origen, la resolución judicial puede ser provisional o definitiva.

- En los Reglamentos vigentes, los motivos de oposición a la ejecución establecidos en Derechos nacionales son los mismos al margen del modelo de fuerza ejecutiva (sea exequátur o fuerza ejecutiva directa). Existen dos reglas comunes a la oposición a la ejecución: la prohibición de discriminación por origen del título (nacional o de otro Estado europeo) en las condiciones y controles de la ejecución; y la preclusión de las alegaciones posibles para la oposición a la ejecución, limitadas a circunstancias sobrevenidas al título, que no impliquen una revisión ni de la resolución dictada ni del certificado emitido.

- Las exigencias documentales tienden a simplificarse, a través de los certificados estandarizados en los Reglamentos, y a flexibilizarse en las exigencias de traducción instada de oficio por el juez encargado de la ejecución.

- Los mínimos afectan a la ejecución transfronteriza de las medidas cautelares y a las condiciones de las dictadas por el órgano encargado de la ejecución. Las primeras están sometidas a los requisitos previos de la notificación y control de la competencia del tribunal de origen. Las segundas pueden dictarse directamente, sin autorización previa, por el juez de ejecución cuando la resolución sea ejecutiva en el Estado requerido.

116 Por ejemplo, resoluciones que tengan que ser objeto de inscripción registral de instituciones desconocidas, tales como la hipoteca judicial provisoria o la hipoteca asegurativa (GASCón INCHAUSTI, op. cit., nota 30 , p. 164).

117 Tipo las freezing orders y las Mareva injunctions (GAScón InchausTI, F., op. cit., nota 56, p. 165); Kramer, X., «Article 54», en Magnus, U. y MANKowski, P., European Commentaries on Private International Law (ECPIL), Brussels I bis Regulation, vol. I, Colonia, Dr. Otto Schmidt, 2016, pp. 969 y ss., esp. p. 971.

118 Por ejemplo, las astreinte del Derecho francés. 
32. La contraposición entre los modelos de fuerza ejecutiva (basados en el exequátur o en la ejecución directa) permite advertir algunas diferencias en relación con la ejecución forzosa:

- Los certificados de la resolución son documentos subsanables, y sin fuerza vinculante en cuanto a su contenido, cuando se requiere exequátur. Son insustituibles en todos los supuestos de ejecución directa y aquí tienen fuerza vinculante, excepto en el ámbito Bruselas I bis.

- En la fuerza ejecutiva directa, el título de origen habilita para la adopción de medidas cautelares en el Estado de la ejecución; sin embargo, en caso de exequátur, antes de obtener la declaración de fuerza ejecutiva, solo pueden adoptarse medidas cautelares con los requisitos del Derecho nacional.

- El exequátur permite un conocimiento de la resolución por el deudor previo a su ejecución, hecho que no está asegurado en los modelos de fuerza ejecutiva directa, excepto en Bruselas I bis.

- La impugnación del título ejecutivo por el deudor impide, en los modelos de exequátur, la adopción de medidas ejecutivas, al contrario de lo que sucede en los modelos de fuerza ejecutiva directa.

- El modelo de exequatur requiere una separación en dos fases en el Estado de la ejecución para los motivos de oposición frente al título y para la oposición a la ejecución forzosa, distinción que desaparece en el modelo de fuerza ejecutiva directa de Bruselas I bis.

33. Se advierten diferentes estándares de protección de los derechos de defensa del deudor no siempre justificados. En particular:

- Los modelos de fuerza ejecutiva directa no garantizan una notificación previa de la resolución judicial para permitir su cumplimiento voluntario por el deudor ejecutado, excepto Bruselas I bis y el Reglamento núm. 606/2013, que exigen la notificación previa del certificado.

- Tampoco se garantizan del mismo modo en todos los Reglamentos las posibilidades de oponerse a la ejecución, dado que solo Bruselas I bis y el Reglamento núm. 4/2009 recogen un derecho del deudor ejecutado a la traducción de la resolución.

34. Finalmente, en relación con la ejecución forzosa, la normativa de desarrollo de la LEC presenta algunas deficiencias que deberían subsanarse; entre ellas:

- La falta de homogeneidad en las reglas de competencia territorial y objetiva para la ejecución forzosa.

- El carácter preceptivo de la traducción de la documentación en todos los casos, no compatible con el tenor de los Reglamentos europeos.

- La falta de garantía de notificación del certificado, en el marco de Bruselas I bis, con carácter previo a la adopción de medidas ejecutivas.

- La ausencia de integración en el mismo procedimiento de los motivos de la denegación de la ejecución del art. 45 de Bruselas I bis y de las causas de oposición del Derecho nacional, con consecuencias en el planteamiento de los recursos. 


\section{RESUMEN}

\section{LA EJECUCIÓN FORZOSA DE LAS RESOLUCIONES JUDICIALES EN EL MARCO DE LOS REGLAMENTOS EUROPEOS}

La ejecución forzosa de las resoluciones judiciales sigue dependiendo de los Derechos nacionales, pero está sujeta a ciertas condiciones derivadas de los Reglamentos europeos. De un estudio comparado de los diferentes Reglamentos, se han obtenido una serie de pautas comunes que constituyen un mínimo europeo en materia de ejecución. La coexistencia de exequátur y fuerza ejecutiva directa afecta a cuestiones de procedimiento, pero las causas de oposición basadas en el Derecho nacional son las mismas en ambos casos. Se advierten diferentes estándares de defensa del deudor ejecutado, en particular una especial protección del mismo en el ámbito de Bruselas I bis. Finalmente, el desarrollo de los Reglamentos en la legislación española presenta algunas deficiencias que deberían subsanarse.

Palabras clave: ejecución forzosa, resolución judicial, exequátur, título ejecutivo europeo, ejecución directa, denegación de la ejecución.

\section{ABSTRACT \\ ENFORCEMENT OF JUDGMENTS IN THE FRAMEWORK OF THE EUROPEAN REGULATIONS}

Enforcement of judgments still depends on national laws of Member States, but it is subject to certain conditions resulting from European Regulations. From a comparative study of the different Regulations, a series of common guidelines have been obtained which constitute a European minimum in the field of the enforcement. The coexistence of exequatur and direct enforcement affects procedural issues, but the grounds for refusal available on national law are the same in both cases. There are different standards of defense of the executed debtor, in particular a special protection under the Recast Brussels I Regulation. Finally, the implementation of the Regulations in Spanish law has some deficiencies that should be corrected.

Keywords: enforcement, judgment, exequatur, european enforcement order, direct enforcement, refusal to enforcement. 